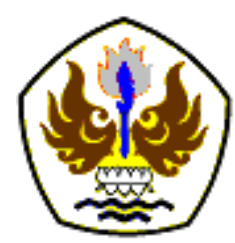

INFOMATEK

Volume 22 Nomor 1 Juni 2020

\title{
PERANCANGAN ALAT BANTU PEMINDAHAN BRAKE CYLINDER DI DEPARTEMEN SARANA KERETA API PT. PINDAD (PERSERO)
}

\author{
Ragil Pardiyono*), Cut Ivo Errent Zairda \\ Universitas Jenderal Achmad Yani, Bandung, Indonesia
}

\begin{abstract}
Abstrak: PT. PINDAD (PERSERO) merupakan Badan Usaha Milik Negara yang memproduksi alat utama sistem persenjataan TNI dan peralatan industri. Departemen Sarana Kereta Api merupakan bagian PT. PINDAD (PERSERO) yang mendukung produksi internal, memenuhi permintaan pasar lokal/ekspor sistem pengereman kereta api.Terdapat satu komponen yang pengerjaan perakitan, pengujian tidak sesuai SOP yaitu Brake Cylinder. Target waktu tidak tercapai pada kegiatan transportasi saat operator mengambil material dari mesin rakit yang dibawa ke mesin pengujian, dan membawa material dari mesin pengujian ke penyimpanan dengan selisih waktu 9 menit. Ini disebabkan oleh faktor manusia, operator mengalami kelelahan fisik karena belum tersedia alat bantu. Nilai $\mathrm{LI} \geq 3$, aktivitas menimbulkan cedera tulang belakang. Masalah diatasi dengan merancang alat bantu pemindahan Brake Cylinder. Metode yang digunakan yaitu metode rasional. Desain disesuaikan dengan dimensi meja uji, rakit, dan dimensi produk lain. Anthropometri dan persentil yang digunakan yaitu tebal telapak tangan genggam (50\%) dan tinggi siku berdiri (50\%). Katrol untuk mengangkat produk (mannual chain block), meja penahan sebagai penyangga (besi plat hitam), roda untuk memindahkan alat (Duty Polyurethane), rangka atas (besi baja H Beam), rangka samping (besi kotak), engsel (rel sliding). Biaya untuk membuat 1 unit alat bantu ini sebesar Rp 8.264.000,--
\end{abstract}

Kata kunci: Work System, Tools, Brake Cylinder, Rational Method, Anthropometry

\section{PENDAHULUAN}

Departemen Sarana Kereta Api merupakan bagian PT. PINDAD (Persero) yang mendukung produksi internal, memenuhi permintaan pasar lokal/ekspor sistem pengereman kereta api. Departemen Sarana Kereta Api bertugas menguji dan merakit komponen-komponen penyusun Air Brake System (sistem pengereman Kereta Api). Komponen yang dirakit dan diuji yaitu

\footnotetext{
*) ragil.pardiyono@lecture.unjani.ac.id
}

Pertama diterima: 26 Februari 2020

Direvisi:16 Maret 2020

Disetujui untuk publikasi: 22 Mei 2020
Distributor Valve, Brake Cylinder BG, Bracket, Emergency Brake Valve, Brake Coupling, sedangkan komponen yang hanya dilakukan pengujian yaitu Slack Adjuster, Isolating Cock, Brake On-Off Device, Air Reservoir, Dummy Coupling Type Gotha. Setelah semua komponen dirakit dan diuji, selanjutnya komponen penyusun Air Brake System dikirim ke PT. INKA (Industri Kereta Api) untuk dirakit menjadi Air Brake System.

Berdasarkan wawancara dengan Kepala Departemen SARKA, mengenai kualitas dan 
waktu pengerjaan perakitan dan pengujian, sebagian besar komponen telah memenuhi standar operasional prosedur. Satu-satunya komponen yang pengerjaan perakitan dan pengujian tidak sesuai SOP adalah komponen Brake Cylinder. Berdasarkan SOP, lamanya waktu proses perakitan dan pengujian Brake Cylinder selama 62,5 menit, tetapi pada kenyataannya berdasarkan pengukuran dilapangan selama beberapa minggu lamanya proses perakitan dan pengujian Brake Cylinder selama 78 menit.

Setelah dianalisis sebab akibat, ternyata tidak tercapainya target waktu proses disebabkan oleh faktor manusia. Waktu yang kurang optimal dapat dilihat ketika operator mengalami kelelahan fisik. Kelelahan fisik yang dialami operator disebabkan karena belum adanya alat bantu material handling, sehingga kegiatan angkut dan pemindahan Brake Cylinder masih manual dengan beban sebesar $40 \mathrm{~kg}$. Hal itu membuat waktu material handling menjadimelebihi standar yang ditentukan. Berdasarkan hasil perhitungan RWL juga menunjukkan nilai LI>3 untuk proses pemindahan Brake Cylinder yang berpontensi menimbulkan resiko cedera maupun sakit pada bagian otot dan tulang belakang. Dari hasil software snook table menunjukkan bahwa beban maksimum (maximum acceptable weight) MAW didapatkan bahwa nilai external load to MAW ration sebesar 3.08, maka hasil tersebut menunjukkan bahwa pekerjaan tersebut berbahaya dikarenakan nilai external load to $M A W$ ration $>1$. Jika dilihat dengan pengujian kuesioner Nordic Boddy Map bahwa pekerjaan tersebut terbukti menyebabkan keluhan pada operator saat setelah bekerja. Maka untuk mengatasi hal tersebut akan dibuat usulan perancangan alat bantu pemindahan Brake Cylinder, sehingga waktu proses dapat tercapai dan resiko kecelakaan kerja dan penyakit akibat kerja dapat dihindari.

\section{METODOLOGI}

\subsection{Recommended Weight Limit (RWL)}

Metode RWL menganalisis terhadap kekuatan manusia dalam mengangkat atau memindahkan beban, dan merekomendasikan batas beban yang dapat diangkat oleh manusia tanpa menimbulkan cedera meskipun pekerjaan tersebut dilakukan secara berulangulang dan dalam jangka waktu yang cukup lama. Recommended Weight Limit (RWL) merupakan rekomendasi batas beban yang dapat diangkat oleh manusia tanpa menimbulkan cidera meskipun pekerjaan tersebut dilakukan secara repetitive dan dalam jangka waktu yang cukup lama (Anggraeni dkk. [1]). RWL ini ditetapkan oleh $\mathrm{NIOSH}$ pada tahun 1991 di Amerika Serikat. (Waters dkk. [2])

a. Beban yang diberikan adalah beban statis, tidak ada penambahan ataupun 
pengurangan beban ditengah-tengah pekerjaan.

b. Beban diangkat dengan kedua tangan.

c. Pengangkatan atau penurunan benda dilakukan dalam waktu maksimal 8 jam.

d. Pengangkatan atau penurunan benda tidak boleh dilakukan saat duduk.

e. Tempat kerja tidak sempit.

Persamaan untuk menentukan beban yang direkomendasikan untuk diangkat seorang pekerja dalam kondisi tertentu menurut $\mathrm{NIOSH}$ adalah sebagai berikut [1], (Novarianto dkk. [3]:

$R W L=L C \times H M \times V M \times D M \times A M \times F M \times C M$

Keterangan :

LC : (Lifting Constanta) konstanta

pembebanan $=23 \mathrm{~kg}$

HM : (Horizontal Multiplier) faktor pengali

horisontal $=25 / \mathrm{H}$

VM : (Vertical Multiplier) faktor pengali vertikal

$=1-0,003$ [V - 75]

DM : (Distance Multiplier) faktor pengali

perpindahan $=0,82+4,5 / D$

AM : (Asymentric Multiplier) faktor pengali

asimentrik $=1-0,0032 \mathrm{~A}(0)$

FM : (Frequency Multiplier) faktor pengali frekuensi

CM : (Coupling Multiplier) faktor pengali

kopling (handle)

\subsection{Metode Rasional}

Metode rasional telah sering digunakan untuk beberapa penelitian tentang perancangan produk, sistem, maupun alat (Kurnianingtyas [4]). Metode rasional dilakukan untuk melaksanakan perancangan secara sistematis pada setiap tahapnya agar hasilnya yang didapat akan maksimal. Penggunaan metode rasional terdpat beberapa tahap seperti klarifikasi tujuan, penetapan fungsi, penetapan spesifikasi, penentuan karakteristik, pembangkitan alternatif, evaluasi alternatif, arsitektur sistem, perancangan konfigurasi, perancangan parametrik, dan perancangan detail (Cross [5]).

Tabel 1. Langkah Metode Rasional

\begin{tabular}{|c|c|c|}
\hline No & Metode Rasional & Tujuan \\
\hline 1 & Klarifikasi Tujuan & $\begin{array}{c}\text { agar tujuan dari penelitian lebih } \\
\text { jelas dan spesifik karena tujuan } \\
\text { dapat meluas }\end{array}$ \\
\hline 2 & Penetapan Fungsi & $\begin{array}{c}\text { untuk menetapkan batasan } \\
\text { rancangan alat }\end{array}$ \\
\hline 3 & $\begin{array}{l}\text { Penetapan } \\
\text { Spesifikasi }\end{array}$ & $\begin{array}{l}\text { untuk memperoleh spesifikasi } \\
\text { kebutuhan yang akurat }\end{array}$ \\
\hline 4 & $\begin{array}{l}\text { Penentuan } \\
\text { Karakteristik } \\
\text { Produk }\end{array}$ & $\begin{array}{l}\text { untuk menentukan target yang } \\
\text { harus didapatkan }\end{array}$ \\
\hline 5 & $\begin{array}{l}\text { Pembangkitan } \\
\text { Alternatif }\end{array}$ & $\begin{array}{c}\text { untuk mendapatkan solusi-solusi } \\
\text { untuk rancangan alternatif }\end{array}$ \\
\hline 6 & Evaluasi Alternatif & $\begin{array}{l}\text { untuk memperoleh evaluasi } \\
\text { terbaik }\end{array}$ \\
\hline 7 & $\begin{array}{l}\text { Perancangan } \\
\text { Konfigurasi }\end{array}$ & $\begin{array}{c}\text { meliputi fungsi dari setiap } \\
\text { komponen penyusun alat bant }\end{array}$ \\
\hline 8 & $\begin{array}{l}\text { Perancangan } \\
\text { Parametrik }\end{array}$ & $\begin{array}{c}\text { meliputi penentuan dimensi alat } \\
\text { angkut }\end{array}$ \\
\hline 9 & $\begin{array}{l}\text { Perancangan } \\
\text { Detail }\end{array}$ & $\begin{array}{c}\text { meliputi hasil rancangan alat } \\
\text { bantu pemindahan Brake } \\
\text { Cylinder dalam gambar teknik } \\
\text { 2D dan 3D }\end{array}$ \\
\hline
\end{tabular}

\subsection{Simulasi Sistem}

Simulasi sebagai cara untuk menghasilkan kondisi dari situasi dengan model untuk studi menguji atau training, dan lain-lain. Khosnevis mendefinisikan simulasi sebagai pendekatan 
eksperimen. Simulasi juga merupakan kumpulan metode dan aplikasi yang digunakan untuk meniru perilaku suatu sistem, kadang dilakukan menggunakan komputer dengan software yang sesuai (Riyanto [6]). Pengertian sistem tergantung pada latar belakang, cara pandang orang yang mencoba mendefinisikannya. Menurut hukum sistem dipandang sebagai kumpulan aturan-aturan yang membatasi baik oleh kapasitas sistem itu sendiri maupun lingkungan tempat sistem itu berada, untuk menjamin keserasian dan keadilan. Schmidt and Taylor dalam Ekoanindiyo [7], mendefinisikan sistem sebagai kumpulan komponen-komponen (entiti-entiti) yang berinteraksi dan bereaksi antar atribut komponen-komponen untuk mencapai suatu tujuan akhir yang logis.

Model didefinisikan sebagai suatu deskripsi logis tentang bagaimana sistem bekerja atau komponen-komponennya bereaksi. Dengan membuat model dari suatu sistem maka diharapkan dapat lebih mudah untuk melakukan analisis (Nasution dan Prasetyawan [8]).

\subsection{Quality Function Deployment (QFD)}

Quality Function Deployment (QFD) diperkenalkan oleh Yoji Akao, Professor of Management Engineering dari Tamagawa University yang dikembangkan dari praktek dan pengalaman industri-industri di Jepang.
Pertama kali dikembangkan pada tahun 1972 oleh perusahaan Mitsubishi di Kobe Shipyard, dan diadopsi oleh Toyota pada tahun 1978, dan tahun-tahun selanjutnya dikembangkan oleh perusahaan lainnya. (Jaelani [9])

Quality Function Deployment adalah metode yang memperhatikan kebutuhan konsumen dan menterjemahkannya kedalam karakteristik engineering (Wagiono dkk. [10]), (Azizah dkk. [11].

Menurut Salis [12] proses QFD meliputi pembentukan matrik-matrik yang juga biasa disebut sebagai tabel kualitas yang memuat tahap-tahap penggunaan QFD yang terdiri atas 4 fasa, yaitu :

1. Perencanaan Produk (Product Planning), meliputi proses penerjemahan karakteristik kualitas yang menjadi keinginan pelanggan menjadi karakteristik teknik perusahaan. Tahap Perencanaan Produk biasa disebut juga The House of Quality. Pada tahap ini dikumpulkan data tentang kebutuhan konsumen, keterangan jaminan, peluang dari persaingan, ukuran produk, ukuran produk pesaing, dan kemampuan teknis organisasi untuk memenuhi setiap kebutuhan pelanggan.

2. Perencanaan Komponen (Part Planning), meliputi proses penerjemahan dan pengembangan karakteristik teknik perusahaan yang dihasilkan pada fasa (1) 
menjadi lebih detail dan membentuk karakteristik kualitas per bagian. Desain produk menghendaki ide team yang kreatif dan inovatif. Konsep produk dibuat selama tahap ini dan menspesifikasi bagian yang telah didokumentasikan. Bagian-bagian yang ditentukan menjadi yang terpenting untuk memenuhi keinginan konsumen yang selanjutnya disebarkan ke dalam perencanaan proses (tahap 3).

3. Perencanaan Proses (Process Planning), meliputi proses penerjemahan karakteristik kualitas pada tiap bagian yang dihasilkan pada fasa (2) untuk menentukan karakteristik proses masing-masing. Selama perencanaan proses, prosesproses manufacturing dijadikan diagram alir dan parameter proses (target values) didokumentasikan

4. Perencanaan Produksi (Production Planning), proses pembentukan hubungan dan keselarasan antara karakteristik proses yang dihasilkan pada fasa (3) dengan karakteristik keinginan bagian produksi. Dalam perencanaan produksi, petunjuk-petunjuk pekerjaan dibuat untuk memantau proses produksi, jadwal pemeliharaan, dan pelatihan keterampilan operator-operator. Selain itu, pada tahap ini dibuat beberapa keputusan untuk menempatkan proses-proses yang paling beresiko dan beberapa kendali ditempatkan untuk mencegah kerusakan

\section{ANALISIS DAN PEMBAHASAN}

Klarifikasi Tujuan dilakukan agar tujuan dari penelitian lebih jelas dan spesifik karena tujuan dapat meluas. Metode yang digunakan yaitu metode pohon tujuan (Objective Tree). Penentuan klarifikasi tujuan menggunakan kuesioner terbuka yang diberikan dengan 5 orang operator sebagai pengguna. Klarifikasi tujuan dapat dilihat pada Gambar 1.

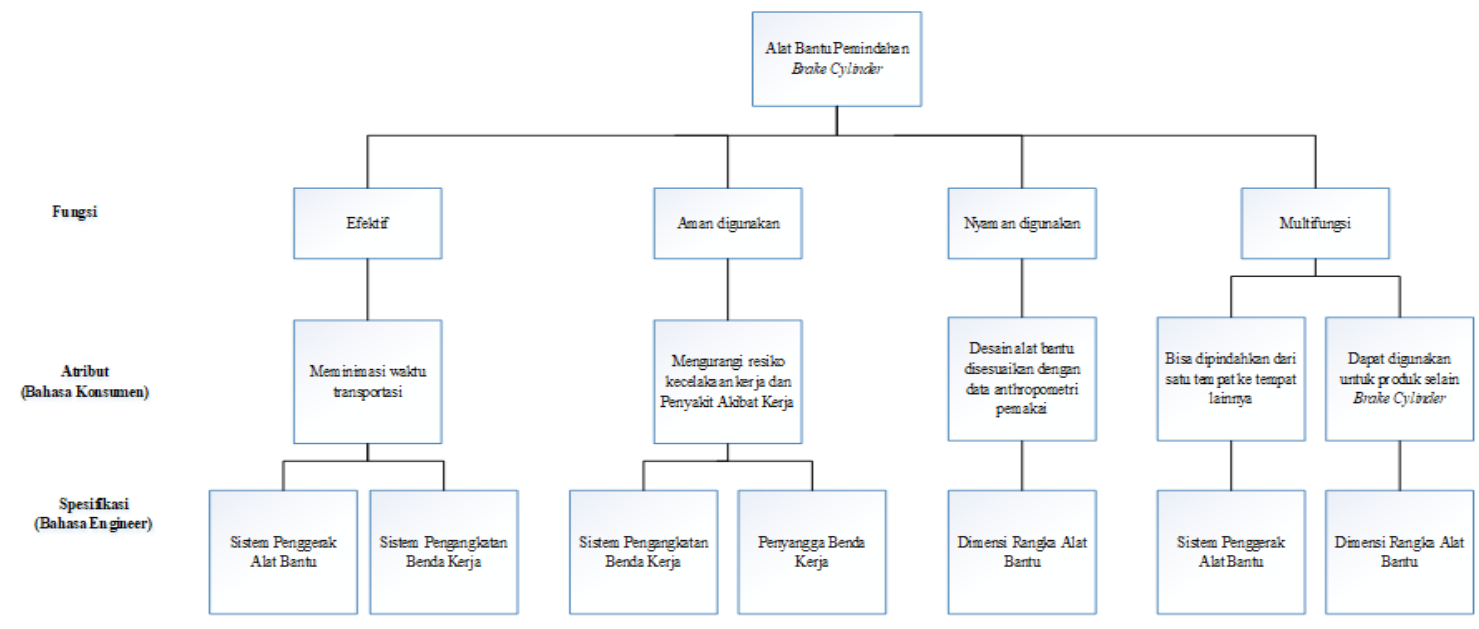

Gambar 1. Pohon Tujuan 
Dari Gambar 1 dapat dilihat pohon tujuan memiliki 3 level. Level 0 sebagai tujuan dari penelitian ini. Level 1 sebagai fungsi dari penelitian. Level 2 sebagai atribut (bahasa konsumen). Level 3 sebagai spesifikasi (bahasa engineer). Penetapan fungsi dilakukan untuk menetapkan batasan rancangan alat. Penetapan fungsi dapat menggunakan metode analisis fungsional. Penetapan fungsi perancangan dalam black box dan transparant box secara berturut-turut dapat dilihat pada Gambar 2 dan Gambar 3.

\section{$\underline{\text { Black Box }}$}

\section{Input}

Brake Cylinder ditempat A

Manusia

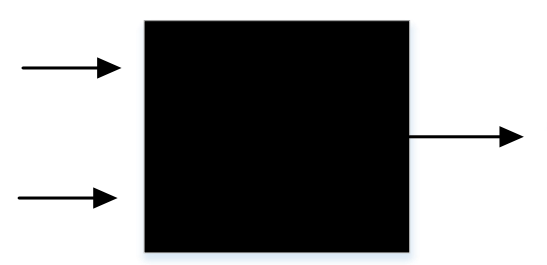

Brake Cylinder dapat dipindahkan ketempat B

Gambar 2. Black Box.

$\underline{\text { Transparant Box }}$

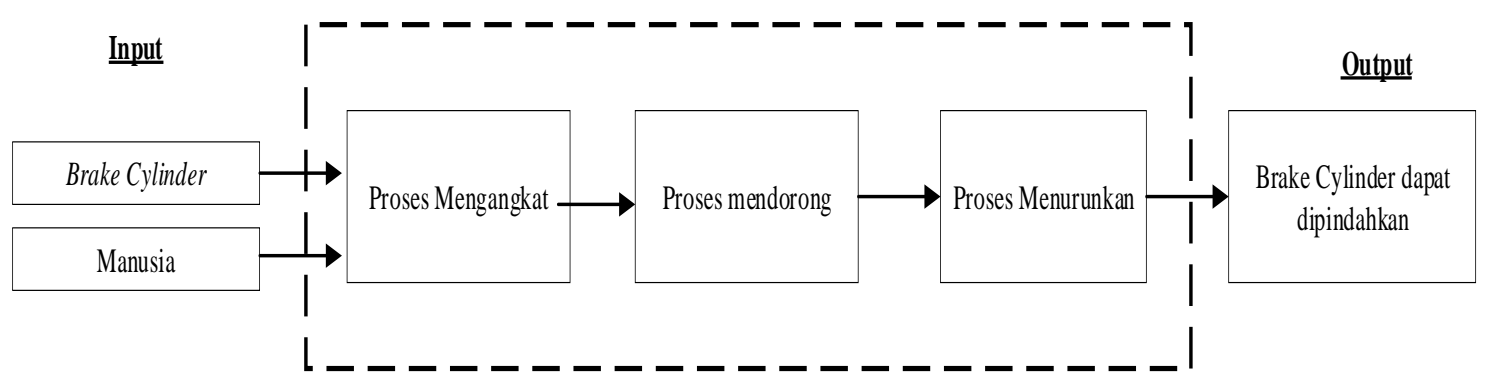

Gambar 3. Transparant Box.

Dapat dilihat pada gambar 2 dan 3, untuk blackbox hanya diketahui input dan oututnya saja tanpa proses. Input nya berupa Brake Cylinder sebagai produk yang diangkat kemudian manusia sebagai penggeraknya. Output berupa tujuan yang didapat seperti alat dapat dipindahkan ke tempat lain. Perbedaan dengan transparant box yaitu sudah dapat dilihat proses menggunakan alat seperti proses mengangkat, mendorong dan menurunkan. Penetapan spesifikasi diperlukan untuk memperoleh spesifikasi kebutuhan yang akurat. Metode yang digunakan yaitu performance spesification mode. Batasan spesifikasi dapat dilihat pada tabel 2 berikut. 
Perancangan Alat Bantu Pemindahan Brake Cylinder di Departement Sarana Kereta Api PT. PINDAD (Persero)

Tabel 2. Penetapan Spesifikasi

\begin{tabular}{|c|c|c|c|}
\hline No & Aspek & Keterangan & Spesifikasi \\
\hline 1 & Berat produk & $>40 \mathrm{~kg}$ & $\begin{array}{l}\text { Sistem pengangkat benda kerja, penyangga produk, dan } \\
\text { rangka harus mampu menahan beban } 40 \mathrm{~kg}\end{array}$ \\
\hline 2 & Tinggi meja uji & $68 \mathrm{~cm}$ & Tinggi penyangga produk tidak boleh kurang dari 68 dan 50 \\
\hline 3 & Tinggi meja rakit & $50 \mathrm{~cm}$ & $\mathrm{~cm}$ \\
\hline 4 & Panjang meja uji & $100 \mathrm{~cm}$ & \multirow{2}{*}{ Panjang rangka tidak boleh kurang dari 100 dan $64 \mathrm{~cm}$} \\
\hline 5 & Panjang meja rakit & $64 \mathrm{~cm}$ & \\
\hline 6 & Lebar meja uji & $45 \mathrm{~cm}$ & \multirow{2}{*}{ Lebar rangka tidak boleh kurang dari $45 \mathrm{~cm}$} \\
\hline 7 & Lebar meja rakit & $45 \mathrm{~cm}$ & \\
\hline 8 & Lantai produksi & $\begin{array}{l}\text { Tidak memiliki long } \\
\text { travel yang Panjang }\end{array}$ & $\begin{array}{l}\text { Lantai produksi tidak memungkinkan dipasang rail karena } \\
\text { keterbatasan tempat. }\end{array}$ \\
\hline
\end{tabular}

Dapat dilihat pada tabel 2 batasan spesifikasi dibuat berdasarkan pertimbangan yang dilihat di lantai produksi Departemen Sarana Kereta Api, sehingga alat bantu yang dirancang nantinya harus dapat memenuhi batasanbatasan yang telah dibuat. Penentuan Karakteristik Produk berfungsi untuk menentukan target yang harus didapatkan. Metode yang digunakan yaitu metode quality function development yang dapat menyatukan antara keinginan konsumen dengan karakteristik tekni. Metode zero one untuk melihat hubungan antar atribut seperti pada gambar 4.

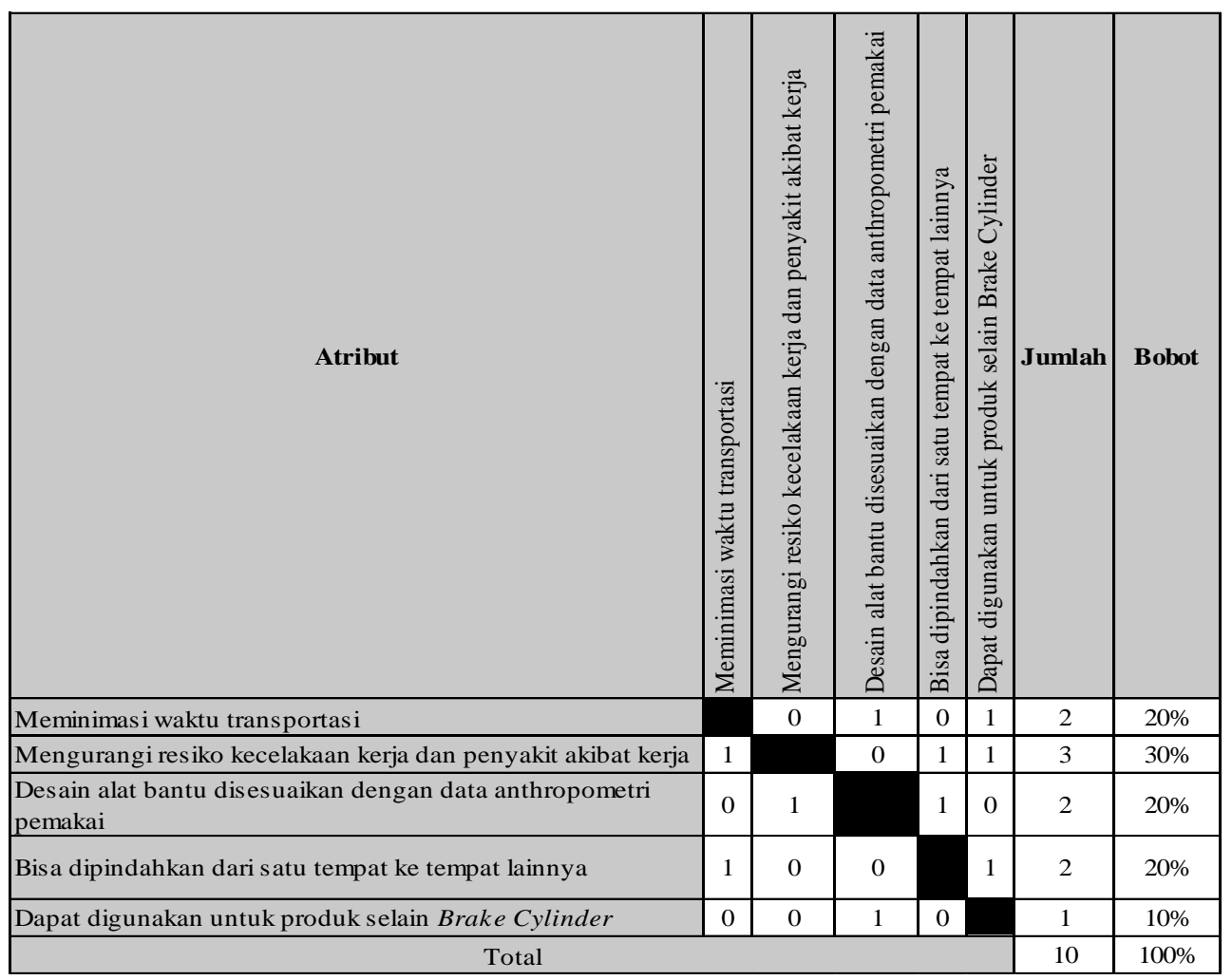

Gambar 4. Metode Zero One 
Selain metode zero one, langkah selanjutnya yaitu membuat rumah kualitas (house of quality) untuk melihat hubungan antara karakteristik teknik dengan atribut. Rumah kualitas dapat dilihat pada gambar 5 .

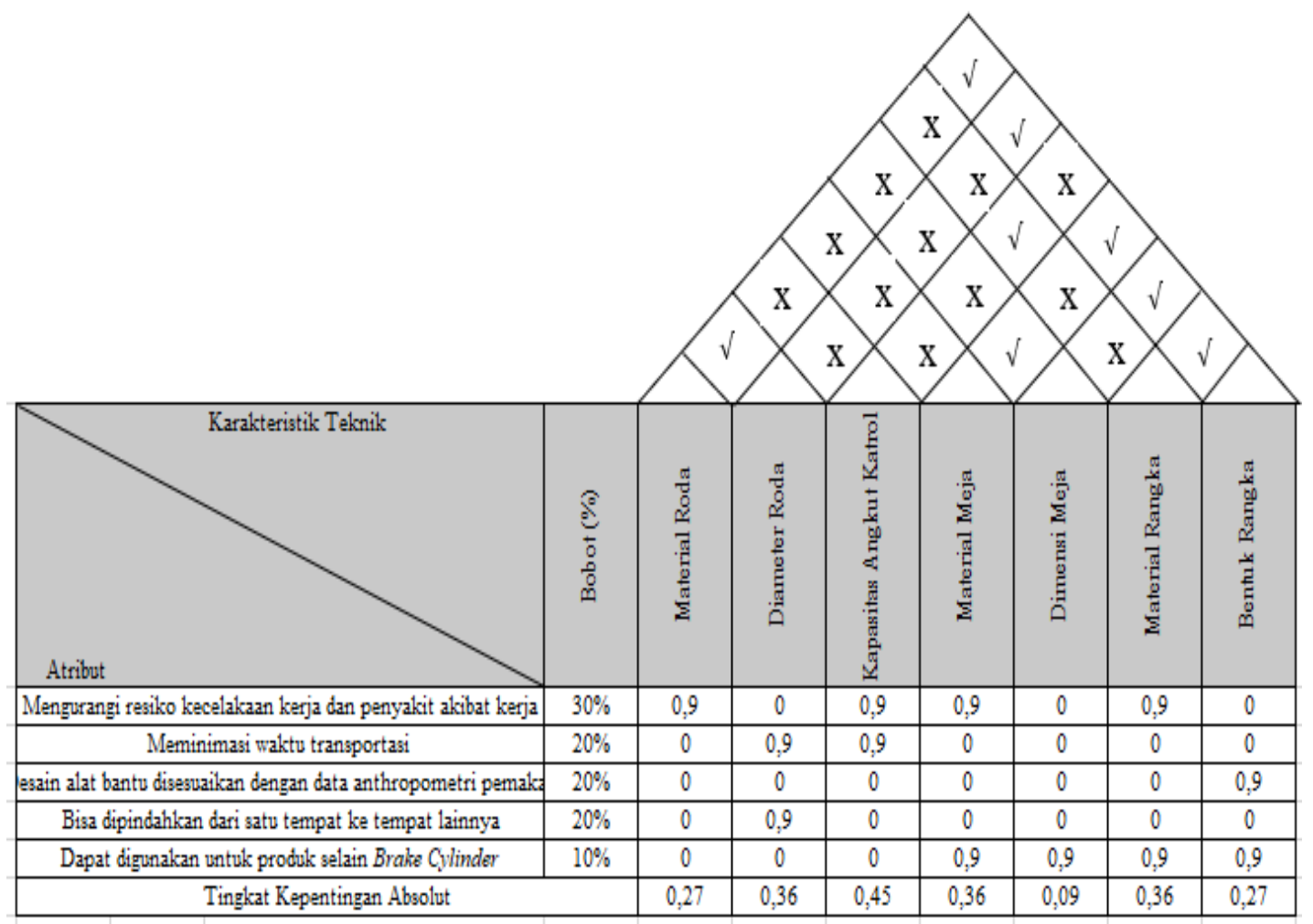

Gambar 5. Rumah Kualitas

Metode untuk pembangkitan alternatif yaitu menggunakan morphological chart. Pembangkitan alternatif ini bertujuan untuk mendapatkan solusi-solusi untuk rancangan alternatif. Pembangkitan alternatif dapat dilihat dalam tabel 3 berikut.

Tabel 3. Pembangkitan Alternatif

$\begin{array}{ccc}\text { No } \begin{array}{c}\text { Karakteristik } \\ \text { Teknik }\end{array} & \text { Alternatif } 1 & \text { Alternatif 2 }\end{array}$




\begin{tabular}{|c|c|c|c|c|}
\hline No & $\begin{array}{l}\text { Karakteristik } \\
\text { Teknik }\end{array}$ & Alternatif 1 & Alternatif 2 & Keterangan \\
\hline 2 & Diameter Roda & Diameter $20 \mathrm{~cm}$ & Diameter $10 \mathrm{~cm}$ & $\begin{array}{l}\text { Diameter } 20 \mathrm{~cm} \text { : lebih tinggi namun perlu } \\
\text { disesuaikan lagi dengan bentuk ranga dan } \\
\text { dimensi rangka, harga lebih mahal jika } \\
\text { dibandingkan dengan diameter } 10 \mathrm{~cm} \\
\text { Diameter } 10 \mathrm{~cm} \text { : lebih rendah namun perlu } \\
\text { disesuaikan lagi dengan bentuk dan dimensi } \\
\text { rangka, dan harga juga lebih murah }\end{array}$ \\
\hline 3 & $\begin{array}{c}\text { Kapasitas Angkut } \\
\text { Katrol }\end{array}$ & 1 Ton & 2 Ton & $\begin{array}{l}1 \text { Ton: kapasitas angkut katrol untuk mannual } \\
\text { chain block paling kecil yaitu } 1 \text { ton, harga lebih } \\
\text { murah dibandingkan dengan yang } 2 \text { ton. } \\
2 \text { Ton: kapasitas angkut katrol untuk mannual } \\
\text { chain block setelah nya yaitu ada pada } \\
\text { kapasitas } 2 \text { ton, harga lebih mahal } \\
\text { dibandingkan dengan yang } 1 \text { ton }\end{array}$ \\
\hline 4 & Material Meja & Besi Plat Hitam & Kayu Triplek Blockboard & $\begin{array}{l}\text { Besi Plat Hitam: memiliki ketahan yang kuat } \\
\text { untuk menahan produk dan kualitas bagus } \\
\text { untuk digunakan dalam jangka panjang. } \\
\text { Kayu Triplek Blockboard: memiliki ketahanan } \\
\text { yang kuat hanya saja tidak tahan dalam } \\
\text { jangka panjang. }\end{array}$ \\
\hline 5 & Dimensi Meja & $\begin{array}{l}\text { Panjang } 116 \mathrm{~cm} \times \text { Lebar } \\
45 \mathrm{~cm} \text {, Ketebalan } 25 \mathrm{~mm}\end{array}$ & $\begin{array}{l}\text { Panjang } 116 \mathrm{~cm} \times \text { Lebar } \\
45 \mathrm{~cm} \text {, Ketebalan } 40 \mathrm{~mm}\end{array}$ & $\begin{array}{l}\text { Panjang } 116 \mathrm{~cm} \times \text { Lebar } 45 \mathrm{~cm} \text {, Ketebalan } 25 \\
\text { mm: ukuran plat meja paling kecil yang dijual } \\
\text { ada pada ketebalan } 25 \mathrm{~mm} \\
\text { Panjang } 116 \mathrm{~cm} \times \text { Lebar } 45 \mathrm{~cm} \text {, Ketebalan } 40 \\
\text { mm: ukuran plat meja yang dijual setelah } \\
\text { ketebalan } 25 \mathrm{~mm} \text { yaitu sebesar } 40 \mathrm{~mm}\end{array}$ \\
\hline
\end{tabular}

Besi Hollow Galvalume: memiliki ketahanan lebih baik terhadap karat dibandingkan dengan

\section{Galvanis}

Besi Hollow Galvanis: sering menimbulkan korosi dan karatan

7 Bentuk Rangka $\begin{gathered}\text { Rangka pada alternatif } 1 \text { memiliki katrol untuk } \\ \text { mengangkat dan menurunkan produk, } \\ \text { terdapat roda agar alat bisa dipindahkan dan } \\ \text { terdapat meja penahan produk dengan model } \\ \text { geser atau tarik }\end{gathered}$


Metode yang digunakan untuk evaluasi antara alternatif-alternatif yang telah alternatif yaitu weight objectives untuk dibangkitkan berdasarkan bobot tujuan. memperoleh evaluasi terbaik. Metode ini merupakan alat bantu untuk membandingkan Rrekapitulasi hasil perhitungan bobot tujuan dapat dilihat pada tabel 5 berikut.

Tabel 5. Evaluasi Alternatif.

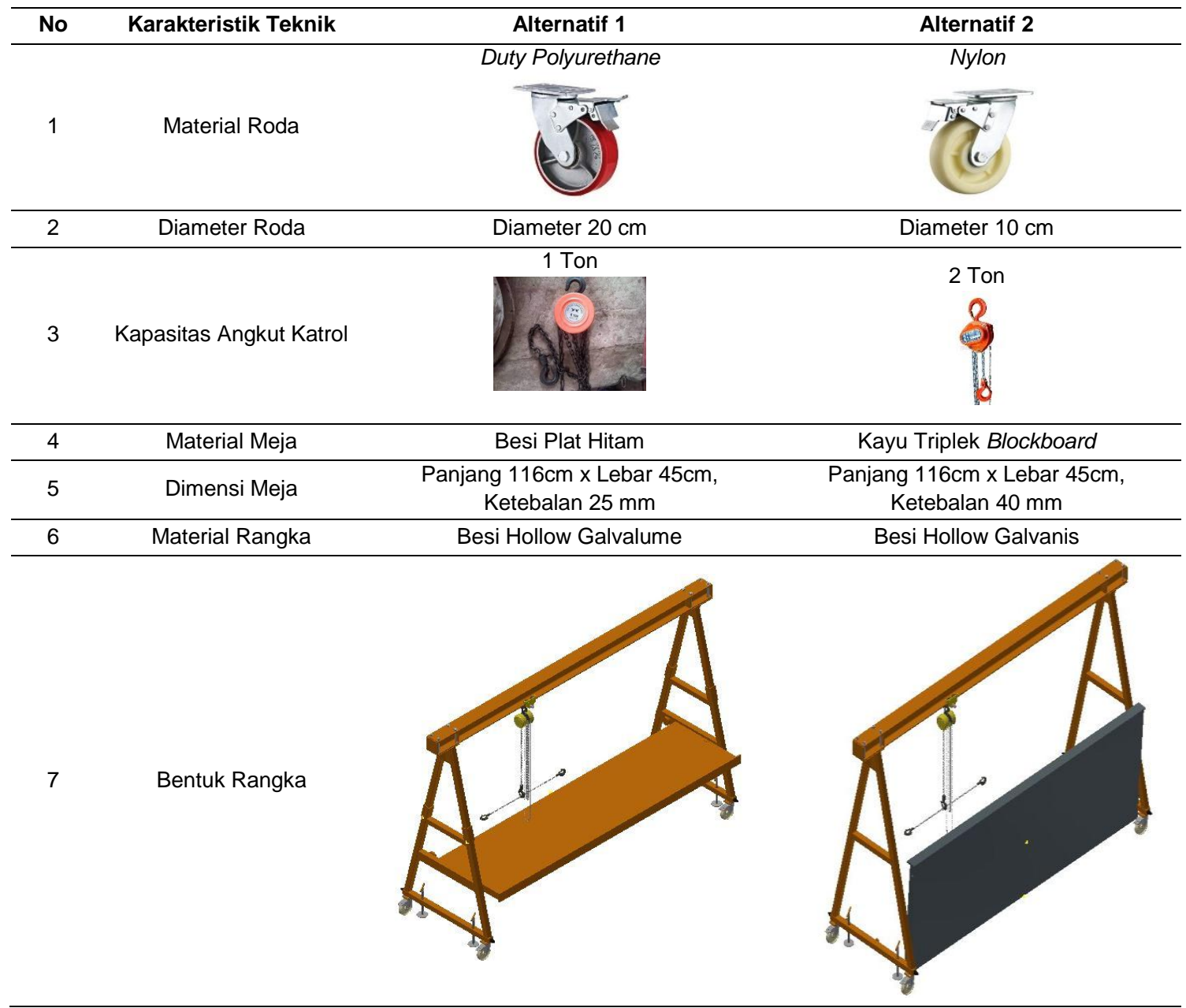

Perancangan konfigurasi, meliputi fungsi dari setiap komponen penyusun alat bantu pemindahan Brake Cylinder. Adapun komponen-komponen penyusunnya yaitu roda, rangka, katrol dan meja penahan produk. Roda difungsikan sebagai sistem lanju alat bantu. Rangka dijadikan sebagai kekuatan utama penopang keseluruhan beban, sehingga diperlukan bahan yang benar-benar kuat untuk menopang 
keseluruhan beban. Katrol difungsikan sebagai sistem pengangkatan untuk mengangkat Brake Cylinder dan komponenkomponen penyusun Air Brake System lainnya. Meja penahan Brake Cylinder difungsikan untuk penopang Brake Cylinder.

Perancangan parametrik, meliputi penentuan dimensi alat angkut dengan mempertimbangkan data dimensi produk lain selain Brake Cylinder, data dimensi produk meja. Dalam penentuan dimensi alat bantu menggunakan data anthropometri seperti tebal telapak tangan genggam (TTTG) dengan persentil $50 \%$ dan tinggi siku berdiri (TSB) dengan persentil 50\%. Data anthropometri yang telah ditentukan dan diambil sampelnya kemudian dilakukan uji keseragaman, kenormalan, dan kecukupan data. Hasil dari uji keseragaman diperoleh data seragam dikarenakan tidak ada data yang out of control. Hasil dari uji kenormalan diperoleh data berdistribusi normal karena nilai Assymp.Sig (2-Tailed) > 0,05. Hasil dari uji kecukupan diperoleh data cukup karena nilai $\mathrm{N}>\mathrm{N}$ '. Perancangan detail, meliputi hasil rancangan alat bantu pemindahan Brake Cylinder dalam gambar teknik 2D dan 3D. Hasil rancangan dapat dilihat pada gambar 5 dan 6 berikut.
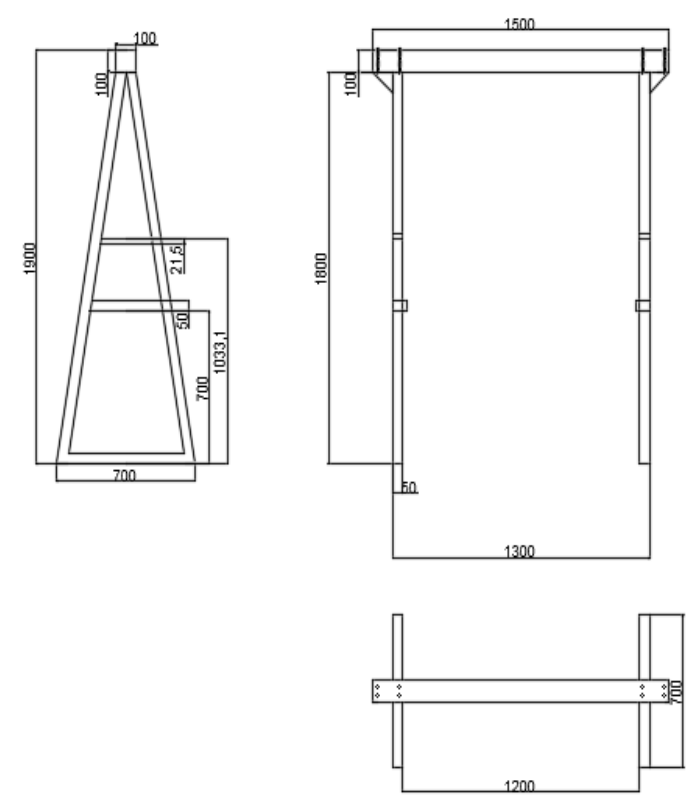

Gambar 5. 2D Alat Bantu Pemindahan Brake Cylinder

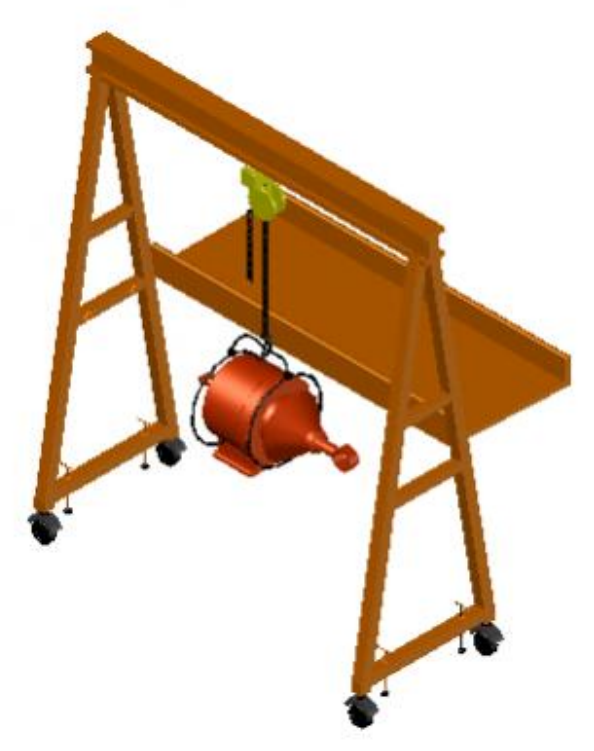

Gambar 6. 3D Alat Bantu Pemindahan Brake Cylinder 
Untuk mengetahui lamanya waktu transportasi dapat dianalisis menggunakan software promodel. Inputan lokasi pada software ini yaitu tempat perakitan, tempat pengujian, tempat penyimpanan, jalan1 dari tempat perakitan menuju tempat pengujian serta jalan2 yaitu dari tempat pengujian menuju tempat penyimpanan. Inputan entitas pada software ini yaitu produk yang akan diangkut dan dipindahkan menggunakan alat bantu. Inputan Processingnya yaitu ketika produk masuk ke stasiun perakitan untuk proses perakitan. Kemudian produk diangkat menggunakan katrol dan dibawa menggunakan alat bantu ke stasiun pengujian untuk dilakukan proses pengujian ketahanan dan kebocoran. Setelah proses pengujian selesai produk diangkat lagi menggunakan katrol dan dibawa ke tempat penyimpanan untuk disimpan. Hasil simulasi dapat dilihat pada gambar 7 dan 8 berikut.

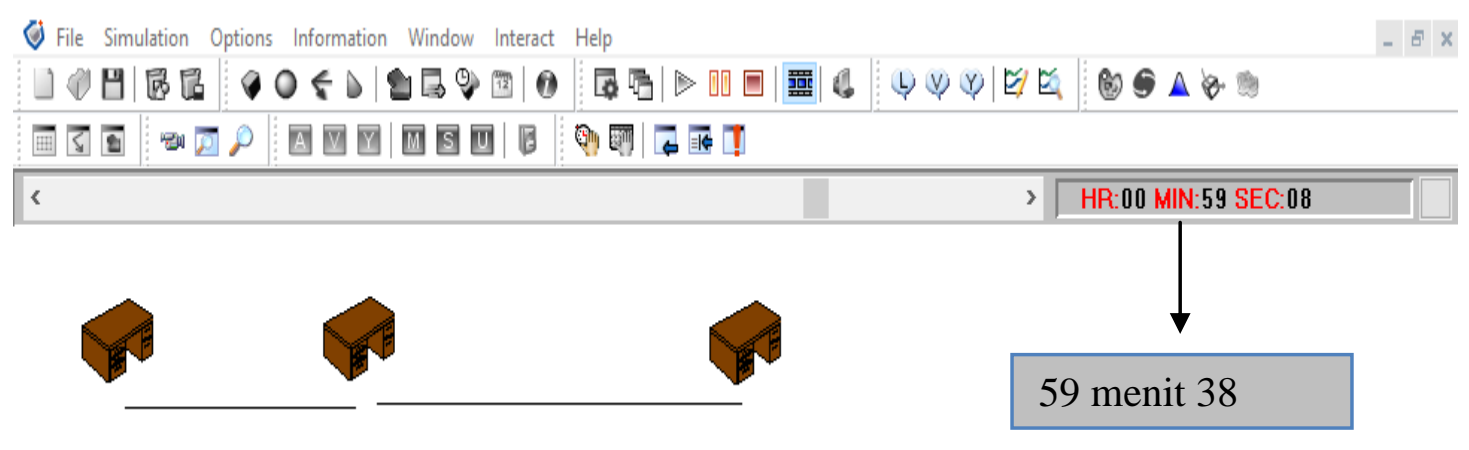

Gambar 7. Simulasi Alat Bantu Pemindahan Brake Cylinder

\begin{tabular}{|c|c|c|c|c|c|c|c|c|c|}
\hline General & \multicolumn{2}{|c|}{ Locations } & Location States Single & \multicolumn{2}{|c|}{ Entity Activity } & \multicolumn{2}{|c|}{ Entity States } & Location Costing & En \\
\hline \multicolumn{10}{|c|}{ percobaanivo.MOD [Normal Run - Rep. 1] } \\
\hline \multicolumn{2}{|c|}{ Name } & \multicolumn{2}{|c|}{ Scheduled Time [NIN] } & Capacity & \multicolumn{2}{|c|}{ Total Entries } & \multicolumn{3}{|c|}{ Avg Time Per Entry [SEC] } \\
\hline \multicolumn{2}{|c|}{ perakitan } & & 59,15 & 1,00 & \multicolumn{2}{|r|}{1,00} & \multicolumn{3}{|c|}{2220,00} \\
\hline \multicolumn{2}{|c|}{ pengujian } & \multicolumn{2}{|r|}{$\begin{array}{l}59,15 \\
59,15\end{array}$} & 1,00 & & 1,00 & \multicolumn{3}{|c|}{930,00} \\
\hline \multicolumn{2}{|c|}{ penyimpanan } & \multicolumn{2}{|r|}{59,15} & 1,00 & \multicolumn{3}{|c|}{1,00} & \multicolumn{2}{|c|}{180,00} \\
\hline \multicolumn{2}{|l|}{ jalan1 } & \multicolumn{2}{|r|}{59,15} & \multicolumn{2}{|l|}{1,00} & \multicolumn{2}{|l|}{1,00} & \multicolumn{2}{|c|}{69,21} \\
\hline \multicolumn{2}{|l|}{ jalan2 } & \multicolumn{2}{|r|}{59,15} & 1,00 & \multicolumn{2}{|r|}{1,00} & \multicolumn{3}{|c|}{149,78} \\
\hline
\end{tabular}

Gambar 8. Report Hasil Simulasi 


\section{KESIMPULAN}

Berdasarkan hasil pengolahan data dan analisis dapat disimpulkan bahwa, komponen penyusun alat bantu pemindahan Brake Cylinder ini yaitu terdapat katrol untuk mengangkat produk, terdapat roda sebagai sistem laju dari alat, terdapat meja penahan sebagai penyangga produk, dan rangka atas/samping sebagai penopang utama keseluruhan dari alat. Biaya yang dibutuhkan untuk membuat 1 alat bantu ini yaitu sebesar Rp. 8.264.700. Berdasarkan hasil evaluasi menggunakan software Promodel diperoleh total waktu keseluruhan untuk 1 unit produk setelah adanya alat bantu ini yaitu 59 menit 8 detik, dengan waktu transportasi sebesar 3,65 menit.

\section{DAFTAR PUSTAKA}

[1] Anggraeni, D.A., Daus, R.A. "Analisis Beban Kerja dengan Menggunakan Metode Recommended Weight Limit (RWL) di PT. Indah Kiat Pulp and Paper. Tbk", Surya Teknika, Vol. 1 No. 4, pp. 49-55, 2016

[2] Waters, T. R., Putz-Anderson, V., \& Garg, A. (1994). Applications manual for the revised $\mathrm{NIOSH}$ lifting equation.

[3] Novariyanto, F., Suparti, E. "Analisis Pengangkatan Beban Air Galon dengan Pendekatan Fisiologi dan Biomekanika (Studi Kasus: di Toko Sejahtera Surakarta", Tekinfo Jurnal IImiah Teknik Industri dan
Informasi, Vol. 5 No. 1, pp. 42-51, 2016.

[4] Kurnianingtyas, C.D., Heryawan, T. "Rancangan Alat Potong Kulit Bahan Baku Tas dengan Metode Rasional", Jurnal IImiah Teknik Industri, Vol. 17 (2), pp. 99-107, 2018.

[5] Cross, N., \& Roy, R. (1989). Engineering design methods (Vol. 4). New York: Wiley.

[6] Riyanto, O.A.W. "Simulasi Model Sistem Kerja pada Departemen Injection untuk Meminimasi Waktu Work-In-Process", Jurnal IImiah Teknik Industri, Vol. 15 (1), pp. 69-78, 2016.

[7] Ekoanindiyo, F. A. (2011). Pemodelan Sistem Antrian Dengan Menggunakan Simulasi. Jurnal Ilmiah Dinamika Teknik, 5(1).

[8] Nasution, A. H., \& Prasetyawan, Y. (2008). Perencanaan dan pengendalian produksi. Yogyakarta: Graha IImu.

[9] Jaelani, E. (2012). Perencanaan dan pengembangan produk dengan quality function deployment (QFD). Jurnal Sains \& Manajemen Akuntansi, 4.

[10] Wagiono, Y.K., Hamrah. "Metode Quality Function Deployment (QFD) untuk Informasi Penyempurnaan Perakitan Varietas Melon", Jurnal Agribisnis dan Ekonomi Pertanian, Vol. 1 No. 2, pp. 48-57, 2007.

[11] Azizah, I.N., Lestari, R., Purban, H.H. "Penerapan Metode Quality Function 
Infomatek Volume 22 Nomor 1 Juni $2020: 1$ - 14

Deployment dalam Memenuhi Kepuasan Konsumen pada Industri Komponen

Otomotif", Jurnal Teknik Industri, Vol. 19

No.2, pp. 127-136, 2018.
[12] Sallis, E. (2014). Total quality management in education. Routledge. 